\title{
Empirical Research on the Application of Online Teaching in Chinese Colleges and Universities Under the Situation of Novel Coronavirus Pneumonia Prevention and Control
}

\author{
https://doi.org/10.3991/ijet.v15i11.13935
}

Zhu Tiejun

Anhui Polytechnic University, Wuhu, China

ztj@ahpu.edu.cn

\begin{abstract}
At the turn of 2019-2020, a new epidemic broke out in China China has entered the critical stage of epidemic prevention and control. And The severe situation has led to the failure of normal opening of the new semester in Chinese colleges and universities. In order to effectively guarantee the education, teaching and talent cultivation in colleges and universities, the Ministry of education of China has rapidly put forward the requirements of launching online teaching. Therefore, under the situation of Novel Coronavirus Pneumonia (Hereinafter referred to as COVID-19) prevention and control, online teaching in Chinese colleges and universities is widely used and develops rapidly. However, the demand for online education has been released in a short time and on a large scale, and each online teaching platform has encountered unprecedented pressure and challenges. In this regard, based on the situation of COVID-19 prevention and control in China, this paper demonstrates how the Chinese government deploy online teaching in an all-round way with specific measures, how the Chinese colleges and universities implement massive online teaching quickly, how teachers and students adapt to online teaching quickly. At the same time, this paper carries out empirical analysis to show the process and effectiveness of online teaching in Chinese colleges and universities in the unprecedented state of COVID-19 prevention and control with specific examples. On this basis, it analyzes and summarizes the advantages and disadvantages, so as to facilitate the later improvement and provide reference.
\end{abstract}

Keywords - Novel coronavirus pneumonia, Chinese colleges and universities, online teaching, application and development, empirical research

\section{Introduction}

In December 2019, confirmed case of COVID-19 was found in Wuhan, China. Due to the fact that it is in the Spring Rush period in China, the floating population is calculated in billion. In the next month, the virus has spread widely in China, and China has entered a state of first-class epidemic prevention and control. As of 8:52am on February 26, 2020, a total of 77788 cases have been confirmed in 31 provinces (regions, cities) 
in mainland China [1], the large-scale outbreak of the epidemic has had a huge impact on China's economy and various industries, among which, although Chinese colleges and universities have already entered the Spring Festival holiday(Winter holiday) in the period of rapid spread of the epidemic, and teachers and students have returned home, however, with the approaching of the new semester opening time, a series of related problems and dilemmas caused by the severe situation of the epidemic in China have brought great impact on China's higher education, which is mainly reflected in two aspects:

On the one hand, it has led to the failure of normal opening of the new semester in Colleges and universities. According to the data of the 2019 national education development statistical bulletin issued by the Ministry of education of China, as of July 2019, "the total number of students in all kinds of colleges and universities in China has reached 38.33 million" [2], and the number of students involved in all kinds of schools has reached an amazing 276 million. It can be seen that only the abnormal start of the new semester will have a serious impact on China's education (Table 1).

Table 1. Schedule of opening time of colleges and universities in 31 provinces or cities of Chinese Mainland under the influence of the COVID-19

\begin{tabular}{|c|c|c|}
\hline No. & Province/City & Opening Time \\
\hline 1 & Anhui & No earlier than March 1 \\
\hline 2 & Zhejiang & No earlier than March 1 \\
\hline 3 & Guizhou & No earlier than March 1 \\
\hline 4 & Hainan & No earlier than March 1 \\
\hline 5 & Guangxi & No earlier than March 1 \\
\hline 6 & Yunnan & No earlier than March 1 \\
\hline 7 & Heilongjiang & No earlier than March 1 \\
\hline 8 & Xichuan & No earlier than March 1 \\
\hline 9 & Jiangsu & No earlier than March 1 \\
\hline 10 & Chongqiong & No earlier than March 1 \\
\hline 11 & Gansu & No earlier than March 1 \\
\hline 12 & Shongdong & No earlier than March 1 \\
\hline 13 & Shanghai & No earlier than March 1 \\
\hline 14 & Guangdong & No earlier than March 1 \\
\hline 15 & Neimenggu & No earlier than March 1 \\
\hline 16 & Hebei & No earlier than March 1 \\
\hline 17 & Jiangxi & No earlier than March 1 \\
\hline 18 & Qinghai & No earlier than March 1 \\
\hline 19 & Xizang & Early March \\
\hline 20 & Hunan & No earlier than March 2 \\
\hline 21 & Shangxi & No earlier than March 2 \\
\hline 22 & Ningxia & Time to be determined \\
\hline 23 & Jilin & Time to be determined \\
\hline 24 & Xinjiang & Time to be determined \\
\hline 25 & Fujian & Time to be determined \\
\hline 26 & Beijing & Time to be determined \\
\hline 27 & Liaoning & Time to be determined \\
\hline 28 & Tianjin & Time to be determined \\
\hline
\end{tabular}


Paper-Empirical Research on the Application of Online Teaching in Chinese Colleges and Universities...

\begin{tabular}{|l|l|l|}
\hline 29 & Hubei & Time to be determined \\
\hline 30 & Shangxi & Time to be determined \\
\hline 31 & Henan & Time to be determined \\
\hline
\end{tabular}

Note: Data as of February 17, 2020, normally, the opening time of colleges and universities in most regions during the winter vacation in 2020 is generally around February 10, and some regions will be different.

On the other hand, it is the chain reaction caused by the delay of the start of new semester: first, how to carry out the epidemic prevention and control work when the massive college and university students return to campus from all over the country; second, will the time of college and university entrance examination and art examination be affected; third, how to apply for employment for college and university graduates; fourth, how to carry out graduation thesis and graduation project for graduates; how to arrange the second round examination for postgraduate entrance examination; fifth, how to arrange the postgraduate entrance reexamination; sixth, how to return to campus in time for foreign students and how to recruit new batch of foreign students, etc. In this regard, the Ministry of education of China has made a comprehensive deployment and positive response to strengthen epidemic prevention and control work. While ensuring the life safety of teachers and students, the Chinese government requires the education authorities and all colleges and universities to implement their responsibilities and management, fully guarantee education and teaching, and do everything possible to minimize the impact of the epidemic. Under this situation, this paper summarizes and analyzes the application and development of large-scale online teaching in Chinese colleges and universities.

\section{Background}

In order to effectively cope with the current situation of the large-scale postponement of the opening and teaching work of Chinese colleges and universities, the Ministry of education of China has issued a policy of online teaching and learning, and requires colleges and universities to do well in education and teaching during epidemic prevention and control through large-scale online teaching. However, a series of problems will be involved in this period, such as: Although China's Internet popularity is very high, "by June 2019, the number of Internet users in China has reached 854 million, an increase of 25.98 million compared with the end of 2018, and the Internet popularity rate has reached 61.2\%" [3] how to set up online courses in remote rural areas? How to solve network congestion and network paralysis? How to ensure the quality and effect of online teaching? and so on.

In response, the Ministry of Education of China has attached great importance to the online opening work of colleges and universities during the epidemic prevention and control. It has placed the top priority in the fight against epidemic prevention and control in colleges and universities. Reduce the impact of the epidemic situation on education and teaching as much as possible. Through the plan of "Internet + Education" deployed in advance, China's colleges and universities have been required to:

First, all colleges and universities are required to prepare carefully, organize carefully, and immediately move from the holiday state to the working state. Leaders at all 
levels should stick to their posts in the campus and command the "battle". Additional staff and teachers work at home and teach online. Each school should do a good job in the comprehensive management of home-based work and teaching according to the local situation of epidemic prevention and control and the actual need of education and teaching. All colleges and universities need to take effective measures, carry out precise policy implementation and classified guidance, timely issue implementation plans and management measures for online school opening, and ensure that online teaching is scientific, orderly and of high quality.

Second, all colleges and universities should adjust the teaching schedule in time according to the actual situation of each school. According to the characteristics of students of different grades, majors and courses, adjust the course flexibly. For ordinary college and university students, adjust and put the theoretical courses suitable for online teaching to the first half of new semester, and adjust the experimental and practical courses unsuitable for online teaching to the second half of this semester; on the premise of not affecting the overall teaching order, individual spring semester courses can be adjusted to the autumn semester. For postgraduates, theoretical course should be offered, and other course should be postponed temporarily. Encourage colleges and universities with better conditions to use virtual simulation experiment teaching.

Third, make thorough preparations for students to return to school offline. Make teaching emergency plan scientifically, and do well in online teaching and offline teaching after students return to school. Teachers should accurately analyze the learning situation, diagnose and evaluate the home-based learning situation and learning quality of students, and revise the teaching plan pertinently, so as to fully connect with the online teaching content in the early stage. Before students return to school, colleges and universities should prepare relatively sufficient emergency epidemic prevention materials, living materials, etc. In particular, all colleges and universities should strengthen the preparation of experiment, practice, training and other teaching conditions so that students can timely get practice teaching after returning to school. All colleges and universities shall, in combination with the actual situation, carefully make the school opening work plan including returning to school, check-in, teaching arrangement, etc., as well as the epidemic prevention and control work plan after the school opening. It is necessary to accurately collect the geographical location, holiday travel information and physical and mental health of students, formulate the staggered peak plan for students of different grades, specialties and regions to return to school, achieve "one student one case", design personalized learning plan for students, comprehensively carry out online teaching, online course self-study, online and offline mixed teaching, and so on.

The fourth is the problems of online teaching resources and quality. On the one hand, it does not encourage every teacher to produce live course during the epidemic period. At the same time, through the live satellite platform of channel 4 of China education television station, it provides course learning resources to users all over the country and will cover remote and poor rural areas, especially those areas where the network signal is weak or cable TV is not accessible. On the other hand, colleges and universities are required to increase the training of online course creation and online teaching for teachers, and strengthen the supervision of online teaching. Through the construction of 
online course in recent years, 24,000 excellent courses (Table 2) of 22 online course platforms are provided to college and university students to ensure the quality of online teaching and play a demonstration leading role. In addition, the Ministry of Education of China also requires all online course platforms to provide technical support services to ensure the smooth application and development of online teaching.

Table 2. Online course platform and number of online courses recommended by the Ministry of Education of China (excluding online courses created by college and university teachers)

\begin{tabular}{|c|c|c|}
\hline No. & Online course platform & $\begin{array}{l}\text { Number of online } \\
\text { courses }\end{array}$ \\
\hline 1 & Icourse & 8000 \\
\hline 2 & Xuetangonline & 2350 \\
\hline 3 & Wisdom Tree & 3223 \\
\hline 4 & Xueyinonline.com & 3464 \\
\hline 5 & Superstarmooc & 480 \\
\hline 6 & Pmphmooc.com & 173 \\
\hline 7 & University Open Online Courses & 471 \\
\hline 8 & CNmooc & 313 \\
\hline 9 & Rong You Xue Tang & 142 \\
\hline 10 & Chinese Moocs & 107 \\
\hline 11 & Umoocs & 99 \\
\hline 12 & Gaoxiaobang.com & 336 \\
\hline 13 & Ulearning.cn & 500 \\
\hline 14 & Mooc.People.cn & 221 \\
\hline 15 & Eicve & 1273 \\
\hline 16 & Chinaacc & 28 \\
\hline 17 & Zhengbao Cloud Classroom & 14 \\
\hline 18 & $\begin{array}{l}\text { Zhejiang Institutions of Higher Learning Online Open Courses Sharing } \\
\text { Platform }\end{array}$ & 23 \\
\hline 19 & Anhui Network Course Learning Center Platform & 582 \\
\hline 20 & Chongqing University Online Open Course Platform & 206 \\
\hline 21 & ILAB-X.com & 2079 \\
\hline 22 & EduCoder & 650 \\
\hline
\end{tabular}

\section{Application and Development of Online Teaching in Chinese Colleges and Universities Under the Situation of COVID-19 Prevention and Control}

Due to the huge impact of the COVID-19, online education and teaching has a blowout phenomenon, "by February 11, 2020, the total number of online users of Ape Tutoring online education platform in China has exceeded 400 million."[4] "In Jiaxing City, Zhejiang Province, Jiaxing smart education cloud classroom has 40 million hits on the day of its launch. " [5] On February 24, 2020, the number of users of Superlearning online platform alone increased by 7 million. All staff of each network education platform are working at full load. They are busy expanding network capacity and 
solving all kinds of online problems to ensure the online needs of hundreds of millions of users. Therefore, the situation of COVID-19 prevention and control has given China's online education application and development of a broad room and unlimited opportunities, but also brought great pressure and challenges. However, in a word, opportunities outweigh challenges.

The application and development of online teaching carried out by the Ministry of Education of China and all colleges and universities are analyzed as follows:

\subsection{Carry out online teaching in an all-round way in Chinese colleges and universities}

Due to the complex composition of college and university students and the staff from all over the country, returning to school is bound to bring great difficulty and pressure to the prevention and control of the epidemic, however, the postponement of teaching will lead to many new problems. Therefore, online teaching has become the best solution to solve the urgent problem. Under the severe situation of COVID-19 prevention and control, the Ministry of Education of China clearly requires that online teaching in colleges and universities should be carried out in an all-round way, and all courses in colleges and universities should be adjusted to online teaching. All colleges and universities should arrange the content and time of online teaching scientifically to ensure the normal teaching work and the healthy eyesight of students. Because of the postponement of the new semester, the school will uniformly pre-register the student's status. After the official notice of returning to school, the student can go back to school and complete the on-site registration.

As mentioned earlier, China's "Internet + Education" plan has been laid out in advance. Therefore, under this special background, this layout has played an important role. With this layout, the Ministry of Education of China has encouraged all colleges and universities to make full use of all kinds of high-quality teaching resources, strengthen cooperation and communication with online teaching platforms, and carry out various forms' online teaching activities, such as web-based autonomous learning, blended teaching, live broadcast courses, etc. Micro-lecture, MOOCs, resource sharing courses, video open courses, teaching resource databases and other high-quality teaching resources approved and constructed by the state, province and school shall be selected as online teaching resources. As the main body of responsibility for teaching content and teaching activities, colleges and universities should establish and implement the system of online course construction, content review, operation guarantee and effective evaluation, and constantly improve the quality of online course.

Colleges and universities with mature conditions can choose live broadcast, MOOCs, Micro courses, Small Private Online Course (SPOC) and other ways to carry out online teaching in combination with various teaching software. Colleges and universities with immature conditions can arrange learning tasks remotely by teachers and conduct them through online tutoring. For the students who are really unable to participate in online learning, colleges and universities should make plans and strengthen one-to-one academic guidance to ensure that one does not fall behind. Considering the network congestion, school should avoid the peak time and try not to open synchronous 
classroom and live broadcast. School should innovate the quality monitoring mode, carry out accurate teaching monitoring for online teaching, and guarantee the teaching effect and the quality of talent cultivation.

During the online opening period, in principle, the teachers take the online teaching and guidance mode. Teachers with online teaching tasks should complete the preparation and teaching work at home. Technical support and management staff returning to school must be registered and approved in advance in strict accordance with the regulations.

\subsection{Scientific arrangement of practical teaching activities}

Due to the impact of the epidemic situation, the original social practice activities in winter vacation have been completely stopped. Therefore, colleges and universities need to conduct a comprehensive investigation of students' experiments, internships and practical training, then adjust the practice teaching activities in time, and prohibit students from going out to participate in all the experiment, practice and training activities including graduation practice and skill competition training. However, social practice is an important link in the cultivation of college and university students. Therefore, on the one hand, the Ministry of Education of China requires students to shift their social practice in winter vacation accordingly, and reduce the credit of social practice in the winter vacation according to the development of the epidemic situation. On the other hand, it also relies on online teaching resources. For colleges and universities with better conditions, they can use the national, provincial and school level virtual simulation experimental teaching demonstration center project to carry out experimental teaching.

\subsection{Online mental health consultation and education}

In addition to its direct destructive impact, the COVID-19 has a great impact on the social and public psychological level, especially on the young college and university students who are active in their thinking and are full of youth. Therefore, on the one hand, colleges and universities have carried out scientific publicity on the situation of epidemic prevention and control as well as health care, and at the same time, they have educated and guided young students in the new era to carry forward the spirit of unity and optimism. On the other hand, all colleges and universities actively organize and carry out epidemic prevention and control courses and psychological counseling courses, and implement the online psychological consultation and hotline service, strengthen the mental health education of teachers and students and provide psychological crisis intervention and service.

Relying on the online mental health education and consultation center, colleges and universities should establish professional counseling service team to strengthen the mental health education for teachers and students during the epidemic prevention and control period, compile "Psychological Response Manual for Teachers and Students in Colleges and Universities During the Epidemic Prevention and Control Period", timely 
provide effective psychological consultation services, and better guide teachers and students to treat it objectively and rationally.

\subsection{Carry out online graduation, employment and entrepreneurship guidance in an orderly manner}

In the current semester, for the graduates of colleges and universities, the course has basically ended, and its main tasks are no more than two aspects: one is to carry out graduation project or graduation thesis; the other is to actively prepare for employment and choose a job position, and the sudden outbreak of the COVID-19, especially for the graduates in the graduation season, has a serious impact. Therefore, China's education administrative department explicitly requires that all colleges and universities should organize the graduation related work of 2020 graduates in a scientific and reasonable way. School can use the Internet to guide students' graduation project or thesis online, and organize and carry out pre-defense, review and other activities of thesis through online video and other ways. Set up the employment information network or related online columns for college and university graduates and release more employment information, so as to provide greater services for promoting online dual selection of graduates' employment and online supply and demand meeting. Colleges and universities also need to coordinate or propose employers to simplify and optimize employment procedures, and adopt e-mail, fax, Internet, video and other means to review resumes, conduct online interview, and sign employment agreements, so as to ensure employment channels as much as possible and reduce the flow of graduates. In addition, local educational administrative departments open online business such as the online replacement of employment registration certificate, online personal files transfer, and so on.

\subsection{Strengthen the technical guidance and service guarantee of online teaching}

For the majority of teachers and students who have not actually carried out online teaching, colleges and universities should actively develop online teaching implementation plan and online teaching work guide, timely organize online training guide teachers and students to quickly master online teaching and learning methods and essentials, and improve teaching effectiveness. Colleges and universities need to pay attention to monitoring the implementation of online teaching, answer and solve various technical problems such as network security and network operation in time, and ensure the safe and stable implementation of online teaching. The establishment of a negative list system of cooperation platforms requires all cooperation platforms to carry out activities in accordance with laws and regulations, to provide high-quality and efficient all-round, personalized services and strong technical support and guarantee for college and university teachers, students and social learners. Arrange specific staff to guide students to make online learning plans, and at the same time identify the performance appraisal and remuneration distribution of online teaching for teachers. 


\subsection{Scientifically and orderly arrange teachers to return to school safely}

Formulate the plan of teachers' returning to campus in a scientific, reasonable and orderly way. Under the condition of ensuring safety, college and university should implement "one teacher one case", and organize teachers not to come back school at the same time. The teachers who cannot carry out online teaching, colleges and universities should coordinate and arrange other teachers in advance to replace and make sure that online teaching does not stop. At the same time, school also should keep in touch with teachers who cannot return to work normally, know their status and return information in real time, and complete the switching of temporary online course teachers in advance.

\section{$4 \quad$ Empirical Research}

In view of the sudden outbreak of the COVID-19 situation, Anhui Polytechnic University, the author's University, with rapid response, comprehensive judgment, on the basis of obtaining the guidance of the provincial government and the provincial education department, in order to minimize the impact of the epidemic situation on students' learning, the university held the epidemic prevention and control work meeting on January 23, 2020, requiring the university's Academic Affairs Office, Modern Technology Center, Library and all schools to actively respond to the delay of new semester and organize online teaching related work. On January 31, the University issued the "Notice on Responding to the Epidemic Situation and carrying out online teaching of undergraduate education in spring semester 2020", which requires each school to define the responsible leadership, and arrange special personnel to be responsible for guiding and implementing the mobilization, organization and implementation of online courses, and guide teachers to actively use Internet information technology to carry out teaching discussion and teaching method innovation, constantly improve teaching design, actively open online courses, and encourage long-term use. In order to promote the organizational work of online teaching in an orderly manner and improve the quality of online teaching, on February 1, the Academic Affairs Office issued the Notice on Strengthening the Online Teaching Course Training, and formulated the online teaching work arrangement to clarify the responsible staff, task content, time node, etc. The specific operation is analyzed as follows:

\subsection{Wide mobilization}

After receiving the notice issued by the University, each school attaches great importance to the mobilization, organization and implementation of online teaching. In order to cope with the situation of epidemic prevention and control, teachers should be organized to change the traditional teaching model, actively participate in the relevant training of online teaching and preparation of online course. Relying on QQ group, Wechat group organized and established by network platforms such as Superstar Learning and Rain Classroom, the number of teachers involved is nearly 800, and the number is increasing. 


\subsection{All parties work together to guarantee}

The University's Academic Affairs Office, Modern Technology Center, Library, Schools and relevant teaching platforms work together. On the one hand, through the real time online classroom monitoring platform of Anhui Polytechnic University, the construction and operation of online courses are monitored in real time. All technical support units provide real time online support services, and teachers' training, data migration and other preparatory work are conducted orderly. On the other hand, it is suggested that teachers should adopt a mixed teaching mode and take classes at different times, appropriately increase students' asynchronous learning before class, i.e. watching and learning online courses, pushing Rain Courseware, and self-study of other materials before class, reduce synchronous online teaching (fixed time live teaching), increase assessment after class, such as pushing exercises to answer online, so as to effectively grasp the learning situation, improve the quality of online teaching and ensure the orderly development of online teaching.

\subsection{Full line start up}

On February 11, 2020, the normal opening time, Anhui Polytechnic University did not stop teaching because of the impact of the epidemic. Thanks to the full preparation and full guarantee in the early stage, the "online" new semester opened in an all-round way. Teachers and students sat in front of computers and began to teach, learn and communicate across time and space. On the one hand, online teaching resources include Superstarmooc, Xuetangonline and other high-quality online course resources recommended by the Ministry of Education of China. On the other hand, more teachers of Anhui Polytechnic University have created 1014 online courses, covering more than half of the theoretical courses of the new semester.

\subsection{Multiple platforms and flexible forms}

Anhui Polytechnic University applies multiple online teaching platforms, including Superstar Learning, Rain Classroom, MOOC, MoocMicro classroom, Alibaba Ding Talk live broadcast, QQ, Wechat, Tencent conference, E-class, Tik Tok etc. According to the characteristics of different online platforms, teachers have developed a set of targeted online teaching programs in combination with their own courses, and carried out online teaching in various forms such as mixed classroom, live broadcast, online discussion, online tutoring and Q \& A, online homework correcting, and so on.

Rain classroom + Superstar learning + QQ group: The advantage of Rain Classroom lies in the effective combination of Wechat and PPT, and the advantage of Superstar Learning lies in the realization of various online teaching tasks, such as attendance in class, live broadcast, question answering, homework, examination, discussion, etc., while the advantage of QQ group lies in the wide popularity, all teachers and students are familiar with and operate freely. Therefore, for courses with strong logicality, calculation and reasoning, such as Advanced Mathematics, PPT courseware can be used to present the logic calculation process of advanced mathematics to students step by 
step in the Rain Classroom. Students can launch real-time bullet screens, send pictures and other interactions, and can realize playback function as well. In addition, through QQ group uploading materials, interactive Q \& A, using Superstar Learning to provide relevant excellent course and MOOCS videos that have been recommended by the Ministry of Education, the organic combination of the three platforms is realized. The organic combination of the three platforms can not only realize online explanation of complex high number formula calculation, but also effectively carry out online Q \& A and assistance for individual students. It can not only realize the online explanation of the calculation of complex advanced mathematics formula, but also effectively carry out the online question answering and assistance of individual students. (See Figure 1)

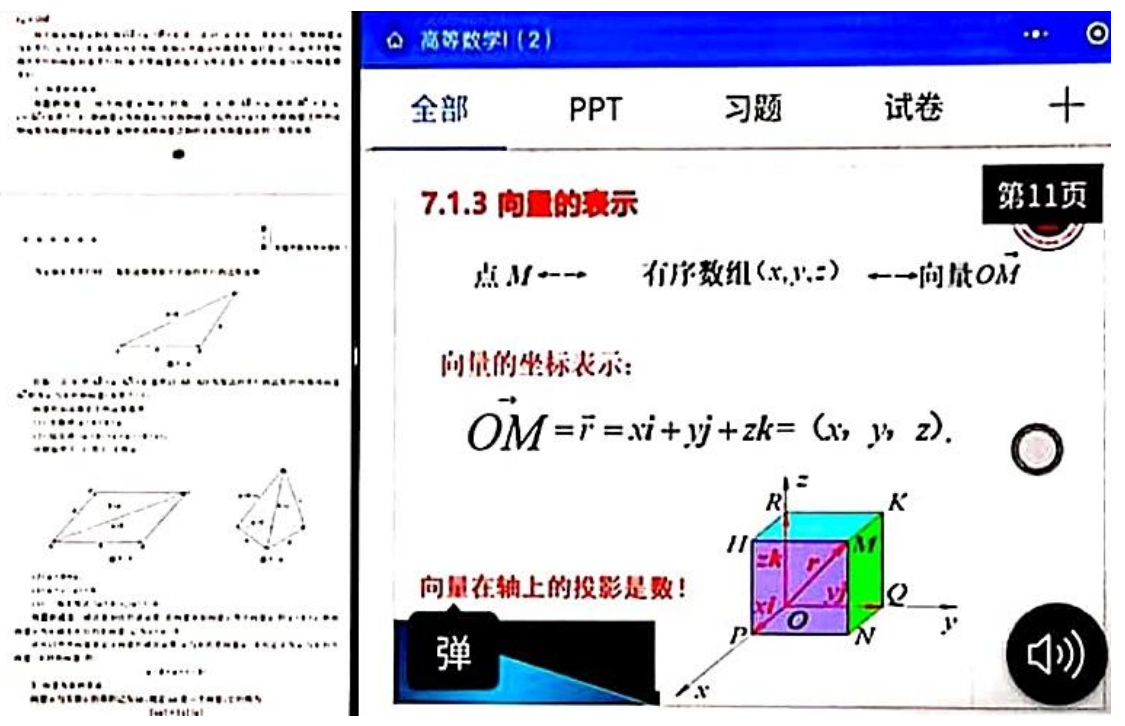

Fig. 1. Online teaching scene of Advanced Mathematics course of Anhui Polytechnic University (Rain Classroom)

MoocMicro classroom + Alibaba ding talk live broadcast: MoocMicro Classroom is an online teaching system independently developed by teachers of Anhui Polytechnic University, which integrates Moocs, Microclass and intelligent teaching platform. Taking online teaching of teacher Xi Lin, the developer of MoocMicro Classroom teaching platform, as an example, she undertakes the teaching course of Mechanical Principle. Because there is no normal start of a new semester, students do not get textbooks, and it is difficult for students to understand Mechanical Principle without multimedia and detailed teaching. Therefore, teacher Xi Lin uses MoocMicro Classroom to make short videos of the key and difficult points of the course and upload them. (See Figure 2) Students can watch the video explanation in advance and repeatedly, and record the difficult problems. In the online class, teacher Xi Lin uses Alibaba Ding Talk live broadcast to teach part of the content of the textbook in combination with PPT and answer questions and exchanging discussions, so that the original very dull and difficult Mechanical Principle course becomes lively and interesting. From the situation that has 
been carried out, students have good feedback. Students have a positive interaction in online classroom, the number of active presentations and questions has increased significantly, and the learning effect has been greatly improved.

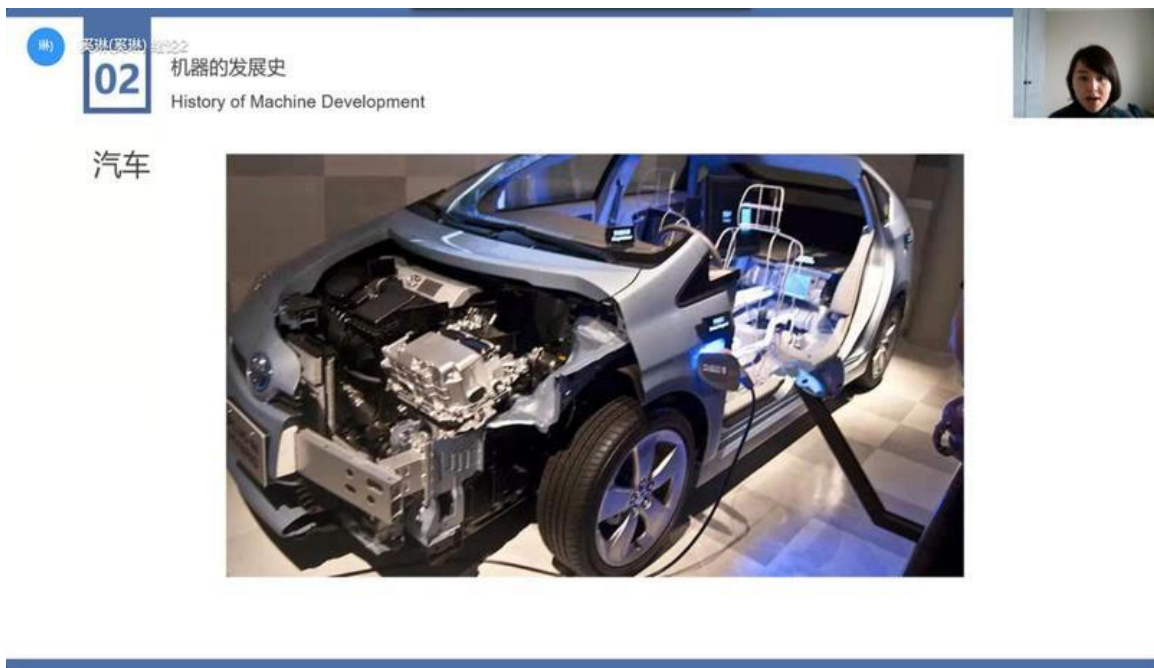

Fig. 2. Online teaching scene of Mechanical Principle course of Anhui Polytechnic University (Alibaba Ding Talk Live Broadcast)

Superstar learning + QQ live broadcast + Wechat: The specialty of art and design is the characteristic specialty of Anhui Polytechnic University. Its design course has high requirements of face-to-face, practical, interactive and counseling. Therefore, online teaching is quite challenging for art and design course. The author is a teacher of Art School of Anhui Polytechnic University, who has been undertaking art and design course for many years. In view of the situation of the epidemic and characteristics of art and design students and courses, the author adopts the way of teaching through Superstar Learning + QQ Live Broadcast + Wechat to carry out online course. The online task function of Superstar Learning platform is powerful, and almost all offline teaching tasks can be realized. (See Figure 3) Therefore, through Superstar Learning platform, daily check-in, questionnaire, assignment, score, test and other functions, as well as audio and video, MOOCs, Micro-lecture and so on, are realized. It not only enriches the learning content, provides students with pre-learning and extensive learning, but also uses the Superstar Learning platform to carry out the supervision of students' class learning and process learning. Another major function of Superstar Learning is to make statistical analysis on all teaching activities. Teachers can make statistical analysis on the teaching process, teaching effect, and even the progress of every student can be seen at a glance. In addition, in the formal online classroom, the author uses QQ live broadcast and screen sharing to show real-time teaching with students. Students are actually watching PPT shared by teacher when facing the screen, and then combining with voice explanation, students are like on-site teaching. Furthermore, voice link and QQ message function stimulate students' enthusiasm for presentation, and students send 
a large number of expression packs and small pictures as well in each online class, it effectively solves the problems of face-to-face and interactive.

$\mathrm{QQ}+$ Wechat can also solve the high requirements of practicality and guidance. The author realizes personalized one-to-one guidance, explanation, discussion and communication with students through such fully popular social software in China. In addition, the author also undertakes the online teaching task of foreign students. Because the foreign student courses are all English teaching, the online teaching platforms recommended by the school are all Chinese versions. The establishment of QQ course group and Wechat course group is an effective way to solve this problem. Online English courses are offered by QQ + Wechat live broadcast and screen sharing.

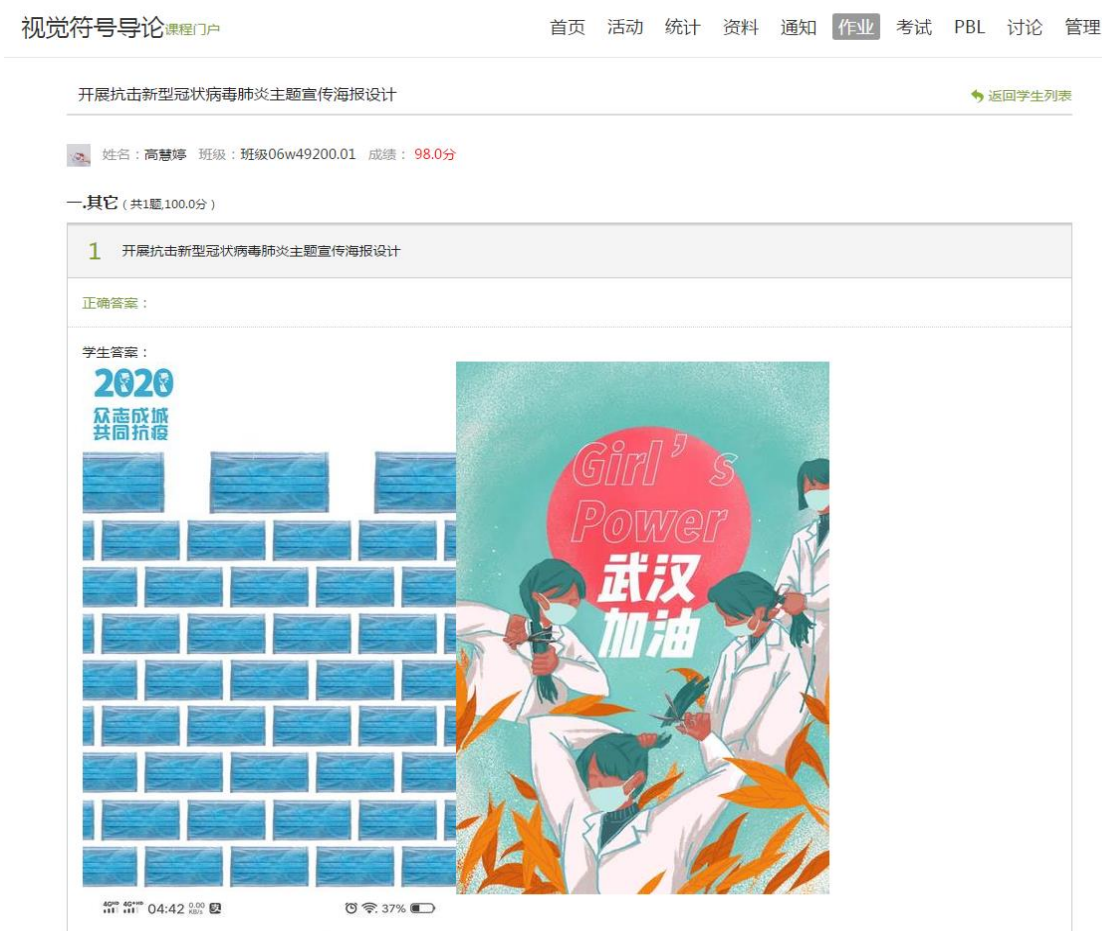

Fig. 3. Online teaching scene of Introduction to Visual Symbols course of Anhui Polytechnic University (Superstar Learning)

Live platform + superstar learning/rain classroom + QQ group: The network live broadcast often gets stuck. A large number of teachers and students open the network live broadcast at the same time, which is likely to cause the online teaching platform to be paralyzed. China's Ministry of education also made it clear that "it is not advocated, encouraged, hoped or suggested that every teacher be required to produce live class during the epidemic period in colleges and universities." [6] In this regard, many teachers of Anhui Polytechnic University have formulated a number of schemes: Live platform is used when the network is smooth, Superstar Learning or Rain 
Classroom is used when the Live platform is congested, and QQ group is used to push learning videos recorded in advance and review materials with text explanation when the Live platform, Superstar Learning and Rain Classroom are all paralyzed. The three solutions can easily cope with the changing network state. For students, they can also combine the three platforms to achieve in-depth communication with teachers, which is not possible in the offline classroom. (See Figure 4).

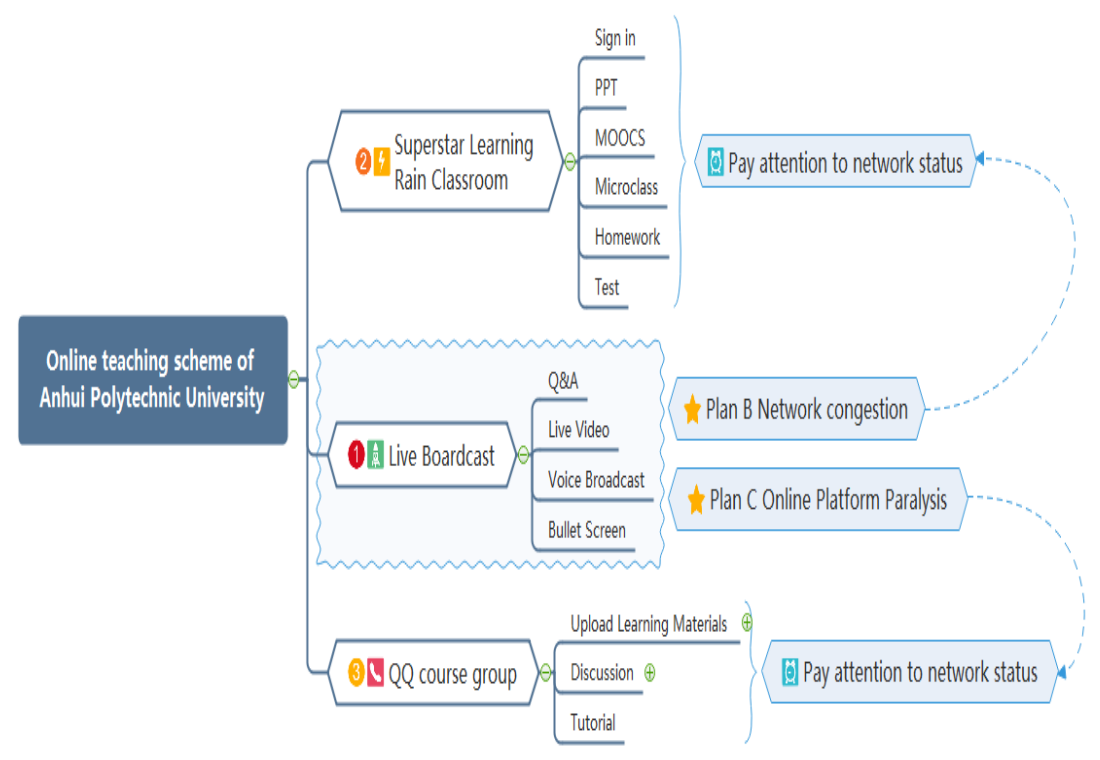

Fig. 4. Flexible online teaching schemes adopted by teachers of Anhui Polytechnic University

E-class +Tik Tok +QQ+ WeChat: "E-class network is a comprehensive interactive community of education, teaching, life service, culture and entertainment in colleges and universities. It provides teachers and students with one-stop educational information services such as home page customization, community communication, space storage, group chat, online learning, activity release, making friends, etc." [7] During the epidemic, Anhui Polytechnic University made full use of this cyber source and platform, relying on the new media matrix of the E-class center, and coordinated with the official website, Student Work WeChat, E-class APP, and E-class Tik Tok, to carry out online epidemic prevention and control publicity and psychological counseling in an all-round way. (See Figure 5) In total, 16 publicity reports were published, including $A$ letter to All the Students, A letter to All the Teachers and Students, Students' Parents and Alumni of Anhui Polytechnic University; 5 articles on "Knowledge About Preventing COVID-19 Infection" were transmitted; 6 notifications were issued, 4 Tiktok original videos of preventing epidemic were produced; and COVID-19 Psychological Epidemic Prevention Manual of Anhui Polytechnic University were published. The total reading amount of above publicity content is nearly 80000 . At the same time, Anhui 
Polytechnic University provides online psychological counseling services for epidemic prevention and control for all teachers and students, and full-time teachers start psychological crisis intervention on duty in advance; QQ dialogue or text is used to carry out online psychological services to help teachers and students effectively cope with the epidemic, eliminate or alleviate the panic and anxiety caused by the epidemic, and set up a strong victory will and determination of the epidemic.

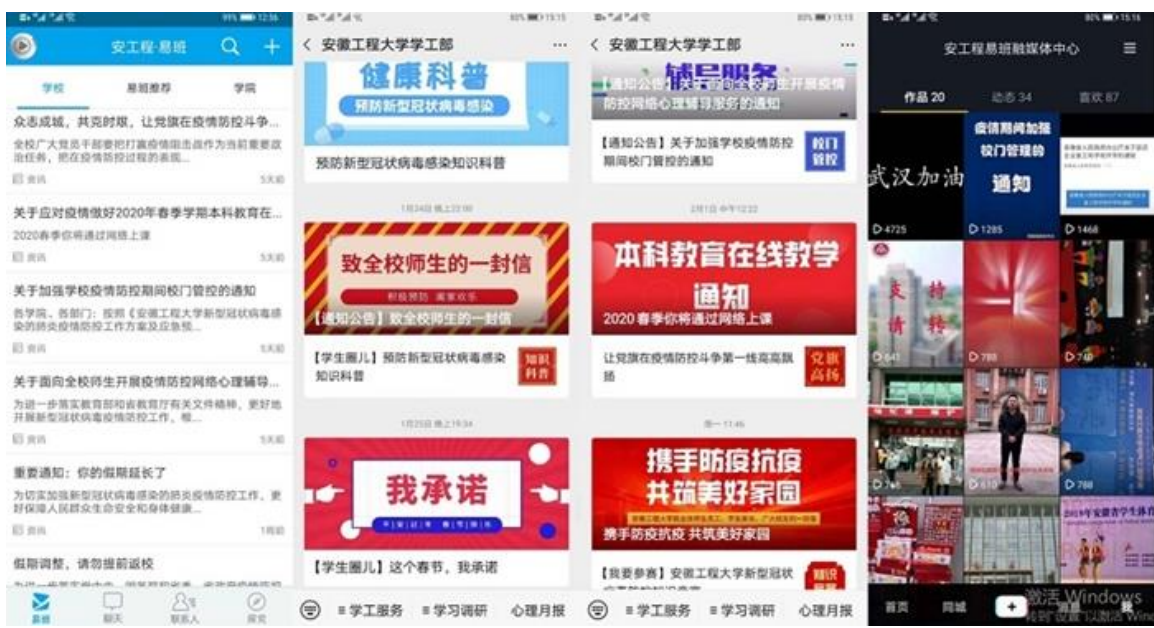

Fig. 5. New media matrix of the E-class center of Anhui Polytechnic University

Online teaching supervision: It is very necessary to carry out online teaching supervision for a large number of online teachers' self-created online courses, and it is also necessary to supervise the students online learning, even for the mature online course recommended by the Ministry of education of China. Under special epidemic situation, the members of the teaching supervision group of Anhui Polytechnic University also changed the traditional mode of on-site supervision, and turned to online supervision. Through online listening and supervision, the supervisors can not only master the online classroom status of teachers and students in the whole process, but also gain a lot from the new online teaching methods. Therefore, the development of online teaching, whether for managers and supervisors, or teachers and students, is a process of learning and improving together. Based on the smooth and high-quality online teaching effect, Anhui Polytechnic University specially issued "A Letter of thanks to Teachers" on February 16, 2020, to thank the teachers who stick to the teaching front line for their great contributions. 


\section{Conclusion}

\subsection{Advantages and effects}

A network cable, a computer or a smart phone has broken through the limitation of time and space. Most importantly, it has effectively solved the education and teaching problems in the extraordinary period of the outbreak of COVID-19. However, it also relies on the persistence and hard work of teachers, managers and technical support personnel. In general, under the situation of the prevention and control of COVID-19, online teaching in Chinese universities has been deeply applied, widely implemented and tested. Its advantages are obvious, but there are also certain disadvantages. The following is a summary from four aspects: students, teachers, management and technology:

First, the use of modern online learning tools and online communication methods are very familiar to Chinese college and university students. The comprehensive popularity of online courses, on the one hand, conforms to the learning habits of Chinese young college and university students, on the other hand, effectively improves the situation that some students dare not ask questions and are shy of doing presentation in face-to-face teaching. With the actual effect of online teaching, students can use kinds of online operations such as bullet screens, pictures, expression packs, small video, voice to actively communicate with teachers and classmates. In an online class, hundreds of communication information appear on the online platform very common. Students become more enthusiastic, more active and more confident.

Second, for college and university teachers, the preparation stage of online teaching has started very early. Teachers have overcome kinds of difficulties in time, such as psychology and technology, and finally entered the practical operation of online teaching in a short time. However, unlike on-site face-to-face teaching, online teaching is not only for students, but also for students' parents and the social public, who may be experts and scholars in some fields. Therefore, open network teaching is a great challenge for college and university teachers. Many teachers are deeply aware of the hardness and difficulty of online teaching preparation, but the harvest is also obvious. The skillful use of online teaching makes teachers' teaching ability stronger; the knowledge is greatly expanded. Furthermore, the special situation in the epidemic prevention and control period makes teachers more responsible, and it is more gratifying that the friendship between teachers and students is reinforced. Because students feel the hard work of teachers through online teaching, countless words of "thank you" flash on the online platform at the end of each class is the greatest reward for teachers.

Third, colleges and universities have not only clarified the process of management, schools and all teachers' overall coordination and close cooperation, but also practiced the full line operation, comprehensive guarantee and quality monitoring of online teaching, found their own shortcomings and gaps, and accumulated rich experience in the arduous task of comprehensively opening online teaching in a short time in a special period.

Fourth, the sudden emergence of COVID-19 makes the original slow evolution model of online teaching in Chinese colleges and universities turn into a rapid 
development. Large-scale actual combat effectively promotes the qualitative change of online teaching platform in higher education, which not only summarizes the experience, but also exposes the shortcomings, and provides a golden opportunity for the later comprehensive improvement and innovation of technical service mode.

\subsection{Disadvantages and deficiencies}

First, the ability of autonomous learning and network knowledge acquisition of college and university students is far stronger than that of primary and secondary school students. Under the influence of the epidemic, the large-scale online teaching with traditional fixed timetable is more about the change of teaching form, but the personalization of teaching content is not high. Therefore, compared with the primary and secondary school students with weak self-control ability and the ability of independent selection of online learning resources, the benefit of this type of online teaching of college and university students is not higher than that of primary and secondary school students. Aiming at the college and university students with great learning difference, the learning significance of some online courses and resources is not strong. It's also not targeted. Resources cause a certain degree of wasting. In addition, long time facing the screen of electronic equipment will not only damage student eyesight, but also visual fatigue is more likely to cause distraction. According to most students' feedback, online courses are easy to be dazed and stupefied when watching and listening, while the teacher cannot know the negative phenomena such as not paying attention to the class or doing other things in real time.

Second, although the teacher' ability can improve greatly in a short time, however, the long-term heavy course preparation task makes teachers pay the high cost of time and energy, and causes great physical and mental pressure. In addition, during the epidemic, teachers created most online courses on their own in a short time, so these courses existed certain problems and were not mature. Unlike the existing excellent course on the online platform recommended by the Ministry of education of China, which had been polished off-line for many times. Some incorrect knowledge explanations and improper words may not only cause teaching accidents, but also may even cause certain social impact.

Third, in order to meet the requirements of the education administrative department to set up online teaching in an all-round way, the management of some colleges and universities has formalism and deal with the situation casually, and the quality supervision of online courses has not been strictly implemented as well. Furthermore, at present, online courses are mostly theoretical courses, and for practical courses, online teaching does not play an effective role.

Fourth, during the epidemic, online platforms are overloaded day by day, and online teaching is not effective in many cases, teaching cannot be carried out normally, the network signal quality is poor, and the congestion and collapse phenomenon of online teaching system platform is serious, which results in a great waste of valuable time resources of teachers and students, and affects the teaching process, the course progress cannot be completed normally, in addition, the technical problems related to personal 
information and privacy protection of teachers and students are not fully kept up in time.

\section{Acknowledgement}

This work is supported in part by the key online teaching reform research project of Anhui Polytechnic University "Research on online implementation and management of international students' intelligent classroom and practical teaching in case of outburst of large-scale epidemic"(2020xsjyxm08); Zhongjiang scholar talent project of Anhui Polytechnic University.

\section{$7 \quad$ References}

[1] National Statistics. Real time situation of COVID-19 epidemic situation (2020), https://ncov.dxy.cn/ncovh5/view/pneumonia?scene $=2 \&$ clicktime $=1579582238 \& \mathrm{en}-$ terid $=1579582238 \&$ from $=$ singlemessage $\&$ isappinstalled=0, Clove Garden, 2020-02-26.

[2] The Ministry of Education of China (2019). 2019 National Education Development Statistical Bulletin, 2019-07-24.

[3] China Internet Network Information Center (2019). 44th statistical report on China's Internet development, 2019-08-30.

[4] Feng Qi (2020). Breaking the classroom wall, Ape Tutoring online education platform has more than 400 million users, Beijing news.com. http://www.bjnews.com.cn/edu/2020/01/ 20/676755.html, 2020-01-20.

[5] Jiaxing Municipal Education Bureau (2020). No suspension of classes" and "Jiaxing wisdom Education cloud classroom "officially launched, Jiaxing education. http://www.jxedu. net.cn/art/2020/2/13/art_html, 2020-02-13.

[6] Pan Zixuan(2020). Ministry of Education: In particular, we do not advocate, encourage, hope or suggest that every teacher should make live class during the epidemic, Xinmin Evening News, 2020-02-12.

[7] E-class (2018). A comprehensive interactive platform for college and university students' study, life and entertainment, E-class.com, http://www.ku68.com/yiban.html, 2018-11-22.

\section{Author}

Zhu Tiejun is an associate professor and graduate student supervisor of Anhui Polytechnic University, Wuhu, China.

Article submitted 2020-02-25. Resubmitted 2020-04-03. Final acceptance 2020-04-04. Final version published as submitted by the authors. 